\title{
Pancreatic Metastasis from Primary Leiomyosarcoma of the Breast
}

\author{
Catarina Félix Miguel Bispo Cristina Chagas \\ Gastroenterology Department, Hospital de Egas Moniz, Centro Hospitalar Lisboa Ocidental, Lisbon, Portugal
}

Keywords

Pancreatic metastasis · Gallbladder metastasis · Breast leiomyosarcoma

\section{Metástases pancreáticas de leiomiossarcoma primário da mama}

\section{Palavras Chave}

Metástases pancreáticas - Metástases da vesícula biliar . Leiomiossarcoma da mama

An 84-year-old female presented with a 3-month history of asthenia, weight loss, and diffuse abdominal pain. Her medical history was remarkable for high-grade breast leiomyosarcoma (Ki67 25\%, $5.5 \times 4 \times 3.5 \mathrm{~cm}$ ) excised 6 years before (R1), with no recurrence during follow-up. Physical examination was significant for pallor and $a b-$ dominal tenderness, and laboratory workup demonstrated anemia ( $\mathrm{Hb} 5.4 \mathrm{~g} / \mathrm{dL})$ and elevated lipase (267 U/L) with normal liver function tests. Ultrasound and a CT scan revealed multiple solid hepatic lesions, the largest measuring $7 \times 5 \mathrm{~cm}$, a $3-\mathrm{cm}$ pancreatic cephalic mass lesion, and a $3.1 \times 2.5 \mathrm{~cm}$ endoluminal mass in the gallbladder (Fig. 1). Differential diagnosis included gallbladder

\section{KARGER}

E-Mail karger@karger.com www.karger.com/pjg
(C) 2018 Sociedade Portuguesa de Gastrenterologia Published by S. Karger AG, Basel

Karcer

0 pen access

This article is licensed under the Creative Commons AttributionNonCommercial-NoDerivatives 4.0 International License (CC BYNC-ND) (http://www.karger.com/Services/OpenAccessLicense) Usage and distribution for commercial purposes as well as any distribution of modified material requires written permission. and pancreatic cancer (eventually synchronous, with liver metastases) and late recurrence of the primary leiomyosarcoma of the breast with liver, gallbladder, and pancreatic metastases.

Endoscopic ultrasound identified solid liver nodules and multiple pancreatic hypoechogenic, well-defined

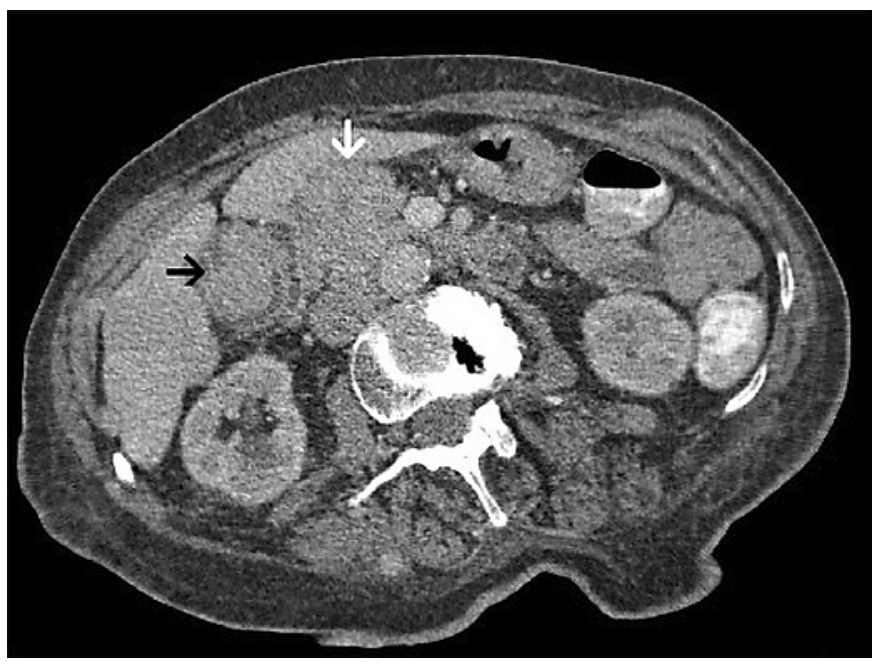

Fig. 1. Abdominal tomography showing a solid pancreatic mass (white arrow) and an endoluminal mass in the gallbladder (black arrow).
Dr. Catarina Félix

Gastroenterology Department, Hospital de Egas Moniz Centro Hospitalar Lisboa Ocidental, Rua da Junqueira no 126 PT-1349-019 Lisbon (Portugal)

E-Mail sfelixcatarina@gmail.com 

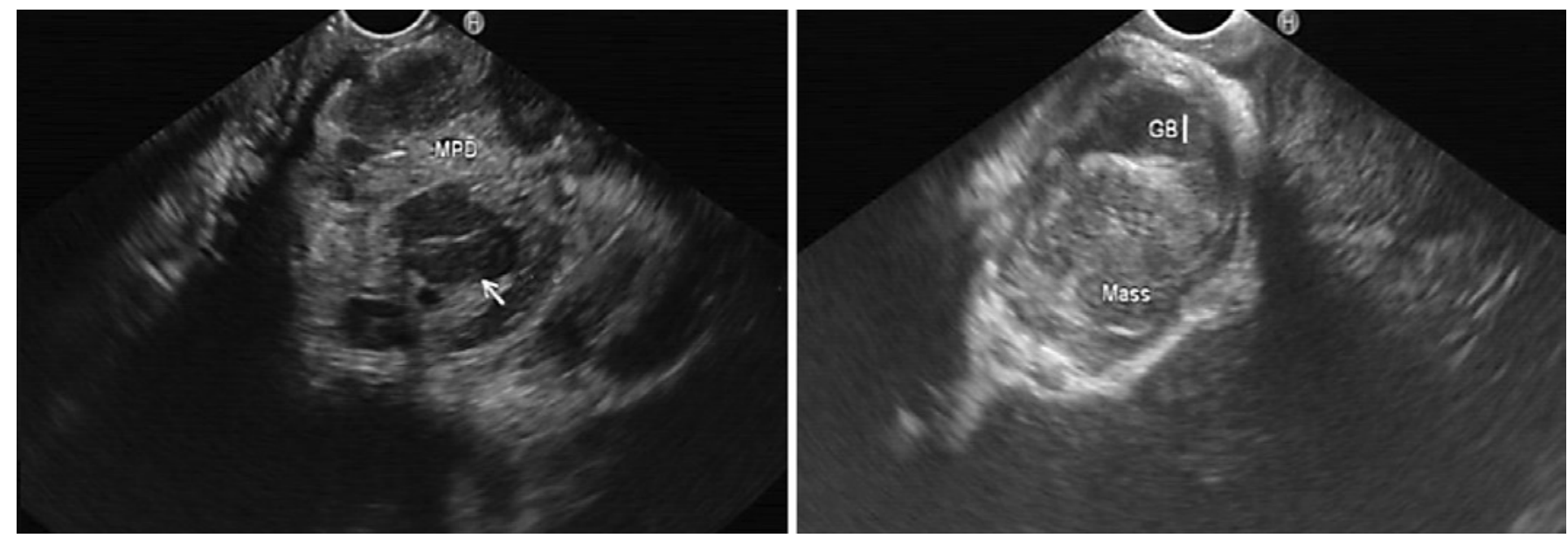

Fig. 2. Endoscopic ultrasound identifying multiple pancreatic hypoechogenic, well-defined nodules (arrow), consistent with pancreatic metastasis, and a heterogeneous hypoechoic gallbladder mass (GB).
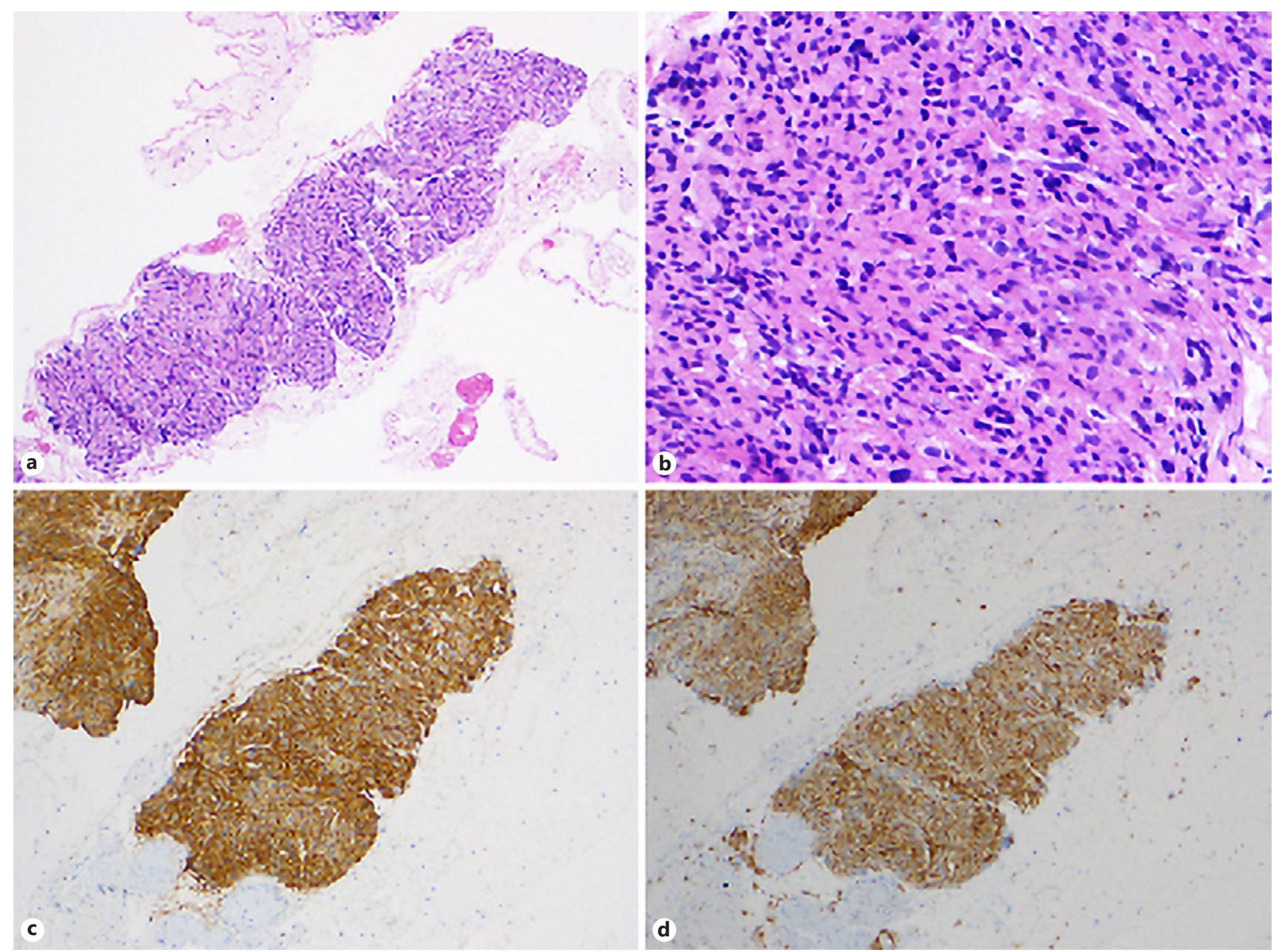

Fig. 3. a, b Fusiform neoplastic cells (HE. $\times 100$ and HE. $\times 400$, respectively). c, d Immunohistochemical staining is positive for actine and caldesmon, respectively. 
nodules, the largest measuring $35 \mathrm{~mm}$ in the cephalic region, consistent with multifocal pancreatic metastization, and a heterogeneous hypoechoic gallbladder mass (Fig. 2). Endoscopic ultrasound-guided fine-needle biopsy of the largest pancreatic lesion using a 22-G needle (Acquire ${ }^{\mathrm{TM}}$; Boston Scientific) was performed. Pathology documented fusiform neoplastic cells with numerous mitosis, and immunohistochemical staining was positive for actine, desmine, vimentin, and caldesmon and negative for CK AE1AE3, Cam 5.2, S-100, and CD99, consistent with pancreatic metastasis from leiomyosarcoma (Fig. 3). The patient was referred to a palliative care unit.

Metastatic gallbladder and pancreatic disease are extremely uncommon in clinical practice $[1,2]$. Melanoma, renal, and cervix cancer are the most common primary cancers associated with gallbladder metastases [1]. Metastatic lesions of the gallbladder from primary breast tumors are rarely described, and most of those have been associated with a lobular histology [1]. Only $2 \%$ of all pancreatic malignancies are metastases, and the most common primary cancer site responsible for pancreatic me- tastasis is the kidney, followed by colorectal cancer, melanoma, breast cancer, lung carcinoma, and sarcoma [2]. Leiomyosarcoma represents an exceedingly rare cause of pancreatic metastasis [3-5], with the primary organs being the uterus, ovary, veins, spermatic cord, intestine, retroperitoneum, and soft tissue [4]. Primary leiomyosarcoma of the breast is an extremely rare form of breast cancer $(<0.01 \%$ of all cases $)$ with an unpredictable biological behavior [5]. To the best of our knowledge, synchronous pancreatic and gallbladder metastasis from breast leiomyosarcoma has never been reported.

\section{Statement of Ethics}

This study did not require informed consent nor review/approval by the appropriate ethics committee.

\section{Disclosure Statement}

The authors have no conflicts of interest to declare.
References
1 Fleres F, Rossito M, Foti A, Macri A, Cucinotta E: Metastasis of the gallbladder from the breast cancer. Ann Ital Chir 2014; 85:S2239253X14023470.

2 Sperti C, Molleta L, Patané G: Metastatic tumors to the pancreas: the role of surgery. World J Gastrointest Oncol 2014;6:381-392.

3 Falconi M, Crippa S, Sargenti M, Capelli P, Pederzoli P: Pancreatic metastasis from leiomyosarcoma of the broad ligament of the uterus. Lancet Oncol 2006;7:94-95.
4 Koh Y, Chul J, Cho C, Kim H: Pancreatic metastasis of leiomyosarcoma in the right thigh: a case report. World J Gastroenterol 2007;13: 1135-1137.

5 Amaadour L, Benbrahim Z, Moumna K, Boudahna L, Amarti A, Arifi S, et al: Primary breast leiomyosarcoma. Case Rep Oncol Med 2013;2013:732730. 